University of Rhode Island

DigitalCommons@URI

Open Access Dissertations

1982

\title{
The Effects of Delayed Response Prevention on Fear Reduction and Enhancement
}

Stephen Abbot Neill

University of Rhode Island

Follow this and additional works at: https://digitalcommons.uri.edu/oa_diss

\section{Recommended Citation}

Neill, Stephen Abbot, "The Effects of Delayed Response Prevention on Fear Reduction and Enhancement" (1982). Open Access Dissertations. Paper 983.

https://digitalcommons.uri.edu/oa_diss/983

This Dissertation is brought to you for free and open access by DigitalCommons@URI. It has been accepted for inclusion in Open Access Dissertations by an authorized administrator of DigitalCommons@URI. For more information, please contact digitalcommons-group@uri.edu. 
THE EFFECTS OF DELAYED RESPONSE PREVENIION

ON FEAR REDUCTION AND ENHANCEMENT

STEPHEN ABBOT NEILL

A DISSERTATION SUBMITTED IN PARTIAL FULFILLMENT OF THE REQUIREMENTS FOR THE DEGREE OF DOCTOR OF PHILOSOPHY

IN

PSYCHOLOGY

UNIVERSITY OF RHODE ISLAND

1982 
ABSTRACT

Long durations of response prevention have been shown to reduce fear in laboratory settings while short durations have been shown to enhance fear. While a review of the literature revealed a number of different parameters which affect the ability of response prevention to reduce or enhance fear, the ability of delayed presentations of the treatment to reduce fear had not been demonstrated. This study examined the effects of delayed presentations of extended response prevention on fear reduction and of short durations of RP on fear enhancement.

One hundred and forty albino rats were randomly assigned to receive extended, brief or no response prevention or to act as nonavoidance trained control subjects. Ten subjects from each treatment condition were randomiy assigned to receive treatment at either 1 min., 1, 7, or 49 days after avoidance training (except control subjects who were treated only at the shortest and longest treatment delay intervals). Fear was assessed immediately after treatment by the approach measures, approach latency and total grid time.

Results consistant with previous findings indicated that fear was reduced following extended durations of response prevention but, unlike previous research, no fear enhancement resulting from brief response prevention was shown. Further, extended treatment was found to produce levels of fear statistically equivalent to controls. Most important, the data suggest that extended response prevention was as effective in reducing fear after long delays as when applied immeoiately after training when the memory of avoidance training remained strong. Implications for therapy analogues were discussed. 
To Theresa and my parents 


\section{ACKNOWLEDGEMENTS}

The influence of a number of people can be seen in this work. I am greatful to my dissertation committee, Nelson Smith, hayne Velicer, James Prochaska and James Loy for their guidance throughout this and other projects. Wayne has been most instrumental in refining my methodological and statistical skills. Both Jim Prochaska and Jim Loy have continually provided diverse points of view which have added breadth to my education. My deepest appreciation is given to my major professor, Nelson, for his guidance, advice, dedication to scholarship, and friendship which he has shared with me over the last five years. Each member has been an excellent role model and I emulate each.

I would aiso like to thank a number of fellow students, specifically, Sally Cottrill, walter Lambert, Tim Mott, Mike Santuri and Paula Vuono for their advice and assistance. Paula deserves special thanks for her conscientious assistance in this study.

My deepest gratitude goes to my wife Theresa whose love, support, and encouragement have allowed me to occasionally tilt at windmills. 


\section{TABLE OF CONTENTS}

LIST OF TABLES

PAGE

LIST OF TABLES

vi.

LIST OF FIGURES

vii.

INTRODUCTION

METHOD

Subjects

13

Appiratus

13

Procedure

Avoidance Training

13

Treatment Delay

Treatment

Fear Assessment

RESULTS

Avoidance Training

Approach Latency without Control Groups 17

Approach Latency with Control Groups 21

Time On Grids without Control Groups 29

Time On Grids with Control Groups 29

The Relationship Between Approach Latency and Time On Grids

REFERENCES 
TABLE

PAGE

1. Incomplete $4 \times 4$ Factorial Design for Testing Fear Enhancement and Fear Reduction at Different Treatment Delays

2. Means and Standard Deviations of Total Trials to 10 Consecutive Avoidance Acquisition Criterion

3. Means and Standard Deviations of Number of Shocked Trials to Avoidance Acquisition Criterion

4. Means and Standard Deviations of Total Shock Duration to Avoidance Acquisition

5. Means and Standard Deviations for Approach Latency (sec.)

6. Means and Stanoard Deviations of Log Transformed Scale for Approach Latency

7. Means and Standard Deviations for Approach Latency (sec.) at Treatment Delay Intervals Including Control Groups

8. Means ano Standard Deviations for Log Transformed Scale for Approach Latency at Treatment Delay Intervals Including Control Groups

9. Means and Standard Deviations for Total Grid Time (sec.)

10. Means and Standard Deviations for Total Grid Time (in sec.) at Treatment Delay Intervals Including Control Groups

11. Means and Standard Deviations for Arcsine Transformed Scale for Total Grid Time at Treatment Delay Intervals Including Control Groups 


\section{LIST OF FIGURES}

FIGURE

PAGE

1. Mean approach latency for treatment groups at each treatment delay interval

2. Mean time on grids for treatment groups at each treatment delay interval 


\section{INTRODUCTION}

Avoidance behavior is functionally defined as a response which prevents or postpones the occurrence of an aversive stimulus. In discriminated avoidance, an animal typically learns to terminate a warning stimulus which would otherwise result in the presence of an aversive stimulus. Most theoretical statements proposed to account for avoidance responding have involved two processes. Generally, one process accounts for the occurrence of the instrumental avoidance response itself by proposing response-outcome contingencies which act as reinforcers for the response. The other process attempts to account for the motivation causing the avoidance response to occur when it does, i.e., in the presence of the warning stimulus. Different theories have proposeo different events within each process and different mechanisms to account for these events as well as different weights for each of the processes in terms of its importance in the generation and maintenance of avoidance responding. These theories can be divided into three general categories: two-processes central state mediation theories (Mowrer, 1940, 1950; Solomon, \& Wynne, 1954; Rescorla, \& Solomon, 1967), single process theories involving the negative reinforcement of the avoidance response (Schoenfeld, 1950; Herrnstein, 1969) and two process cognitive expectancy theories (Bolles, 1970; Seligman, \& Johnston, 1973). (See Neill, 1980; Mineka, 1979 for reviews of each of these approaches).

Mowrer's $(1940,1950)$ two factor fear mediation theory is the most often cited framework for interpreting avoidance behavior (Corriveau, 1978; Mineka, 1979). Mowrer describes the acquisition and maintenance of avoioance as a dual process involving the learning of both a fear 
response and instrumental avoidance response. The theory proposes that fear is learned through classical conditioning by repeatedly pairing the warning stimulus, an effective conditioned stimulus (CS), with the aversive stimulus, an unconditioned stimulus (UCS). Fear, assumed to be a conditioned response (CR), is elicited by CS presentations in the avoidance procedure. The avoidance response itself is thought to be motivated by the fear elicited by the CS and instrumentaily reinforced through fear reduction resulting from termination of the CS. Rescorla, \& Solomon (1967) slightly modified Mowrer's theory by describing the central state elicited by the CS as representing the preoictive contingency between the CS and the UCS. They maintain that this central state is still subject to the laws of classical conditioning ano, as Mineka (1979) has pointed out, this state has retained the label of "fear" when referred to by most researchers.

Experimentally induced avoidance behaviors in animals are generally considered to be more resistant to extinction than other conditioned responses (Solomon, \& Mynne, 1954; Levis, 1966). In the laboratory, extinction of avoidance responses is typically operationalized by removing the UCS while continuing to present the CS. Since the subject continues to escape the CS, there is no opportunity to discriminate between training and extinction conditions. According to Mowrer's theory, the central state representing the predictive contingency between CS and UCS, i.e., the fear state, does not change because fear is generated by CS presentations and reduced by avoidance responding. This results in continued reinforcement for, and thus the persistence of, the response. By escaping prolonged exposure to the $\mathrm{CS}$, the subject removes itself from the very situation in which relearning about the CS-UCS 
contingency might take place. Mowrer (1950) has drawn the analogy between this process and similar processes involved in human neurotic behavior which is often self perpetuating and seif defeating.

It is this persistence of avoidance responding which has caused the most problems for Mowrer's fear mediated avoidance theory. Over a series of consecutive successful avoidance trials, the fear CR should gradually extinguish due to what are, in effect, classical extinction trials where the CS is no longer paired with the UCS. The extinction of fear then should remove the motivation for the instrumental avoidance response, resulting in the cessation of avoidance responding. A number of studies have demonstrated that fear, when measured by the conditioned emotional response (CER) paradigm, is not as great in the latter segments of extended avoidance training as in early segments, indicating a dissociation between fear and extendeo avoidance performance (Kamin, Brimmer, \& Black, 1963; Mineka, \& Gino, 1979b, 1980; Mineka, Miller, Gino, \& Gienche, 198i; Starr, \& Mineka, 1977). However, other studies have demonstrated that the avoidance resporise can be extinguished without a concurrent reduction in fear (Coulter, Riccio, \& Page, 1969; Page, 1955; Page, \& Hall, 1953; Rohrbaugh, \& Riccio, 1970) and under certain circumstances fear can increase with added brief CS exposure (Gordon, Smith, \& Katz, 1979; Linton, Riccio, Rohrbaugh, \& Page, 1970; Rohrbaugh, \& Riccio, 1970; Rohrbaugh, Riccio, \& Arthur, 1972). Despite these findings, Mowrer's theory is cited most often as an explanation for the learning of discriminated avoidance.

Research suggests that fear may motivate behavior in the early stages of avoidance learning but not after the response is well learned (Kamin, et. al., 1963; Mineka, \& Gino, 1979b, 1980; Mineka, et. al., 1981). This 
dissociation between fear and avoidance has lead to theoretical speculation regarding the motivating factors in avoidance from both operant (Hernstern, 1969) and cognitive (Bolles, 1970; Seligman, \& Johnston, 1973) orientations. However, a large number of studies have demonstrated that fear, as measured by CER, passive avoidance or active avoidance, is at least a by-product of avoidance conditioning, even if it is not the only motivating factor (see Corriveau, \& Smith, 1978; Mineka, 1979; Neill, 1980 for more complete reviews).1

Because of the similarities between experimentally induced avoidance behavior in animals and fear motivated neurotic behaviors in humans (Baum, \& Poser, 1971; Leitenberg, 1976; Stampfl, \& Levis, 1967), applied as well as basic researchers have been interested in investigating techniques for eliminating avoidance behavior and reducing the fear which accompanies it. One such technique, called "response prevention" (FP) by Baum (1970) has been used in laboratory settings with animal subjects. This method consists of training an animal to consistently avoid a CS and then preventing the subject from making the avoidance response in the presence of the CS. The UCS is never presented during RP. According to Mowrer's theory, since presentation of the CS is no longer paired with the UCS, fear of the CS extinguishes resulting in extinction of the avoidance response. A large number of diversely designed studies have demonstrated the efficacy of extended periods of $A P$ in facilitating both extinction of active avoidance and a reduction in fear as measured by CER or passive avoidance (see Neill, 1980 for a complete review). Similarly, in applied treatment settings, implosion therapy and flooding, for which $R P$ is the subhuman analogue, have been employed successfully in the treatment of anxiety motivated phobic behaviors (see Baum, \& Poser, 1971; 
Stampfl, 1966 for reviews).

It should be noted that an alternative explanation of the process by which RP facilitates the extinction of avoidance, called the competing response theory, has been proposeo by Page (Page, 1955; Page, \& Hall, 1953). Because RP prevents the occurrence of the originally learned avoidance response in the presence of the CS, new responses, such as freezing and crouching, are instrumentally reinforced through the absence of shock. Thus, when the subject is tested in an active avoidance extinction procedure, it is likely to exhibit these newly learned instrumental responses in the presence of the CS rather than exhibit the originally conditioned avoidance response. Page (1955) contends that, while RP reduces the persistence of avoidance, the reduction does not necessarily demonstrate a reduction in fear. He has used this counter conditioning to explain why active avoidance is extinguished without a concurrent decrease in fear as was found by Coulter, et. al., 1969; Gordon, et. al., 1979; Linton, et. al., 1970; Page, \& Hall, 1953; Page, 1955; Rohrbaugh, \& Riccio, 1970.

While Page's competing response theory does not preclude the possibility of a fear $C R$ extinguishing as a result of extended nonreinforced exposures to the CS, it does cast further doubt on the absence of avoidance responding in an active avoidance extinction paradigm as an adequate index of fear. Accordingly, several researchers have demonstrated that passive avoidance assessment techniques, such as latency to approach a previously avoided CS and the total time a subject voluntarily exposes himself to the CS during a test period, provided the most sensitive measures of fear (Corriveau, 1978; Corriveau, \& Smith, 1978; Mineka, et. al., 1981). It has been demonstrated repeatedly that 
when RP is of sufficient duration, fear, as measured by the approach techniques, is reduced (Corriveau, \& Smith, 1978; Neill, 1980; Neill, Corriveau, \& Smith, Note 2; Neill, Cottrill, \& Smith, Note 3; Neill, Smith, \& Riccitelli, Note 4; Vuono, Neill, \& Smith, Note 5).

These approach measures have also been useful in assessing the enhancement of fear which can result from brief periods of RP. While extended periods of RP are presumed to result in the extinction of fear because the CS is no longer paired with the UCS, brief RP may not be of sufficient duration to allow extinction to occur. Eysenck (1968) noted that these brief CS exposures have the potential to exacerbate fear. This enhancement effect has been empirically demonstrated using the approach measures to assess fear by Linton, et. al., (1970) and Rohrbaugh, \& Riccio (1970) as well as by Rohrbaugh, et. al., (1972) using CER and by Gordon, et. al., (1979) using persistence of avoidance.

Both applied and theoretical interests in methods of fear reduction have lead to a number of parametric studies investigating the efficacy of RP. Factors such as UCS intensity (Corriveau, Note 1), amounts of RP (Mineka, et. al., 1981; Rohrbaugh, \& Riccio, 1970), techniques

facilitating RP (Corriveau, Contildes, \& Smith, 1978), massed versus distributed RP (Schiff, Smith, \& Prochaska, 1972), fear enhancement by brief RP (Gordon, et. al., 1979; Rohrbaugh, et. al., (1972) and the duration of the effects of RP (Benline, \& Simmel, 1967; Neill 1980) have been investigated.

One question that has not been adequately addressed involves the effects on fear reduction of delays in the application of RP after avoidance training. If delayed RP is less effective in reducing fear than the immediate application of the treatment then the implication for 
clinical use of implosion therapy and flooding, which are based on RP procedures, would be obvious. Clinical intuition has always suggested immediate treatment of traumatic phobias to be the most efficient way to eliminate conditioned anxiety. Any oelays in treatment are thought to result in increased anxiety through the incubation of fear (Eysenck, 1968, 1976) and, thus, require prolonged and more difficult treatment. However, no empirical evidence confirms this assumption, either from clinical sources or from animal analogue research.

Central to the problem of how delayed RP affects fear is the degree to which the subject is able to retrieve from memory the original contingencies which came to produce fear. General evidence suggests that conditioned responses can be retained for extended perioos if no intervening events alter the original contingencies or no competing responses are acquired. Marquis, \& Hilgard (1936) and Hilgard, \& Humphries (1938) demonstrated that classically conditioned responses can be remembered up to 16 months for dogs and 19 months for man, while Skinner (1960) reported immediate and correct responding for pigeons on an operant pecking task after six years of inactivity. Specific to the memories of avoidance contingencies, Campoell, \& Campbell (1962) demonstrated little loss of fear as measured by active avoiding in a shuttle box at retention intervals of up to 42 days for rats, while kirby (1963) demonstrated that rats showed no decrement in active avoidance after 50 days. Smith (1968) obtained similar results for an escape response in a T-maze at retention intervals up to 75 days. There is also evidence that fear resulting from active avoidance training in a one-way platform avoidance apparatus does not decrease after 30 days and is still exhibited in decreased amounts at a six month retention interval (Neill, 
Cottrill, \& Smith, Note 3).

If, as these data seem to indicate, the memory of the fear producing contingencies is still as strong after a delay as when it was originally learned, it could be hypothesized that extended periods of RP will be just as effective in reducing fear after the delay as when applied immediately. Similarily, delayed brief periods of RP should be just as effective in increasing fear.

However, evidence also exists that memory decrements after avoidance training can occur (Gordon, et. al., 1979; Kline, \& Spear, 1969, 1970; Spear, 1973; Spear, Hamberg, \& Bryan, 1980). These decrements can be alleviated by a procedure called reactivation (Spear, 1973) or reinstatement (Campbell, \& Jaynes, 1966) which consists of exposing a subject to one or more components of the original learning situation. Further, Spear, et. al., (1980) suggest that the effects of reactivation are greater after extended delays than after short delays. If the original fear producing contingencies have been forgotten prior to treatment, then RP, a procedure which also exposes the subjects to some aspects of the original learning situation, may have the effect of reactivating the original memory of fear.

Research by Gordon, et. al., (1979) suggests that fear can be reactivated by brief durations of RP (up to $75 \mathrm{sec}$. of CS exposure) after forgetting has occurred. They reported that when RP took place within 24 hours of avoidance training, the probability that subjects would avoid on a single test trial decreased while the probability of avoiding was nigher after RP was delayed for 72 or 96 hours. Gordon, et. al. speculated that at the short treatment delay interval when evidence of the original training was strong, prevention of the avoidance response 
resulted in the subject's learning competing response patterns such as freezing. These subjects then exhibited the competing responses during the test trial which resulted in an overall decrement in avoidance responding compared to untreated subjects. However, after forgetting had occurred the brief exposure to the CS in RP at the longer treatment delay intervals served to reactivate the original learning, but was too short to allow for the learning of new competing responses. This accounted for the higher probability of avoidance responding at the longer treatment. delay intervals.

Gordon et. al. (1979) admit that their explanation is speculative. It is further confounded by the demonstration that the original fear was forgotten at 96 nours by nontreated subjects in only one of their experiments. Also, their procedures did not assess the impact of delayed treatment on fear reduction because of the short durations of RP employed. Thus, the ability of RP to reduce fear when introduced at times other than imnediately after avoidance training has not been demonstrated.

The present study was designed to empirically investigate the effects of time of exposure to RP and the length of RP on the reduction of fear, using the fear sensitive approach measures as the dependent variables. Avoidance trained subjects received either $45 \mathrm{~min}$, , $15 \mathrm{sec}$, or no response prevention treatment at delays of either 1 min., 1, 7, or 49 days. In addition, two groups of control subjects who received no avoidance training and $45 \mathrm{~min}$. of $\mathrm{AP}$ at training-treatment intervals of 1 min. or 49 days were included. Thus, the incomplete $4 \times 4$ factorial design, illustrated in Table 1 was employed.

The different durations of RP were chosen to give information about 
TABLE 1

Incomplete $4 \times 4$ factorial design for testing fear enhancement and fear reduction at different treatment delays

TREATMENT DELAY INTERVAL
I MIN.
1 DAY
7 DAYS
49 DAYS

TREATMENT

CONDITION
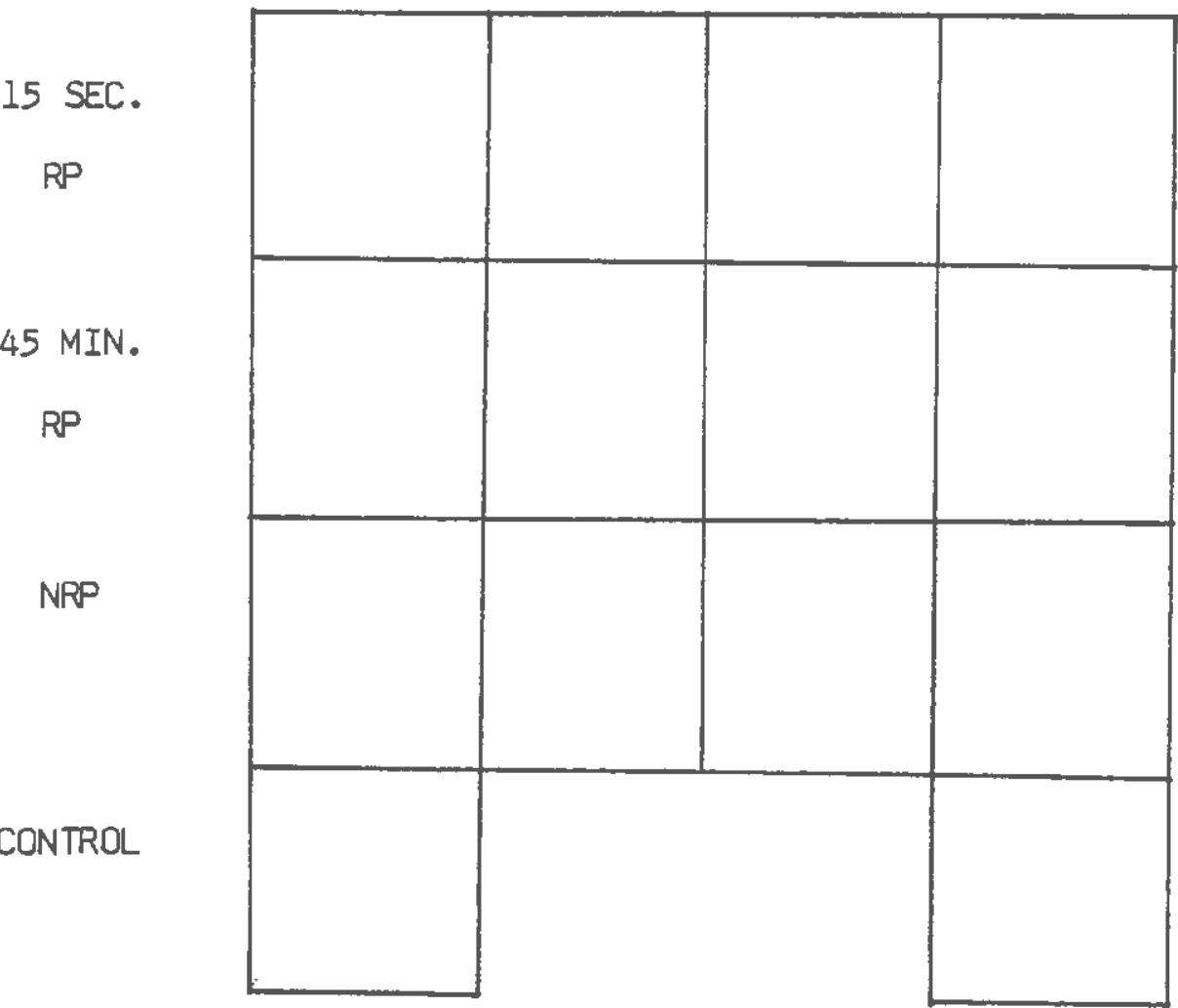

$$
\begin{aligned}
& n=10 \text { for all cells } \\
& N=140
\end{aligned}
$$


the degree to which the amount of CS exposure can reduce or enhance fear. Fear reduction has been best demonstrated at long durations of RP. For this reasons $45 \mathrm{~min}$. of RP, a duration shown by Neill (1980) and Corriveau (1978) to be effective in reducing fear, was chosen. Because short durations of RP have been demonstrated to enhance fear, a $15 \mathrm{sec}$. CS exposure was chosen. This duration was shown to effectively increase fear by Gordon, et. al., 1979; and Rohrbaugh, et. al., 1972. Avoidance trained subjects receiving no response prevention were included to provide a baseline against which fear reduction or enhancement could be measured. The inclusion of non avoidance trained control subjects supplied information about the degree to which response prevention was effective in eliminating fear. It was hypothesized that treatment groups exposed to different amounts of RP would exhibit different amounts of fear; it was predicted that the groups receiving short and long CS exposure would exhibit greater and less fear, respectively, than the untreated groups while the nonavoidance trained control groups would show the least fear.

The ireatment delay intervals were chosen to give information about the effects of RP after a long delay (49 days), an intermediate delay (7 days) and a short delay ( 1 day) as well as, effectively, no delay (1 minute). Because the degree to which subjects remembered the avoidance contingencies was presumed to influence the outcome of treatment, and because evidence of both forgetting and strong retention of fear over these intervals have been demonstrated, different hypotheses regarding the effects of delayed treatment on the amounts of fear exhibited by the subjects were generated.

If forgetting the original training occurred after 7 or 49 days, as 
was demonstrated by Gordon, et. al., (1979), it was predicted that RP would reactivate the memory of avoidance training. Because the memory of the training resulting from the reactivation is greater after extended delays (Spear, et. al., 1980), a greater enhancement of fear at 49 days compared to the enhancement effect seen at the shorter delays was predicted for the group receiving $15 \mathrm{sec}$. of RP. This was predicted for the group receiving $45 \mathrm{~min}$. of the treatment if this duration of RP was insufficient in disconfirming the original avoidance contingency, the memory of which was strengthened by the reactivation. Thus, changes in the amount of fear demonstrated after different treatment delays were hypothesized, with an increase in fear predicted for subjects in each RP group and a decrease in fear predicted for the NRP subjects, because the NPP groups received no reactivation.

However, if little or no forgetting occurred, then no increased reactivation effect was expected. Evidence from Neill (1980) and Campbell, \& Campbell (1962) demonstrated strong retention of avoidance learning (fear) at 30 and 42 days, respectively, by nontreated subjects. If, at 49 days, the memory of fear was strong it was hypothesized that the delay of treatment would have no effect on the amount of fear exhibited. It was predicted that for subjects receiving $15 \mathrm{sec}$. of RP, the amount of fear enhancement would be the same as demonstrated at shorter treatment delays. Similarily, the amount of fear reduction for the group receiving $45 \mathrm{~min}$. of RP would also be equivalent to that at shorter delays. 
METHOD

Subjects

The subjects were 150 experimentally naive male Sprague-Dawley rats obtained from the Charles River Breeding Laboratory. They were housed separately and maintained on ad lib food and water throughout the entire study. Weights at the start of training ranged from 250 to $350 \mathrm{~g}$. Seven subjects were discarded and replaced for failure to meet avoidance training criteria and three were replaced due to equipment failure. Apparatus

All avoidance training, response prevention and fear testing were performed in a one-way platform avoidance apparatus, manufactured by the Lafayette Instrument Company (model 85200), housed in a sound attenuating chamber. The grid chamber was $23 \mathrm{~cm}$. long, $20.3 \mathrm{~cm}$. wide and $20.3 \mathrm{~cm}$. high. The platform, located $9 \mathrm{~cm}$. above the grid floor through an $11 \mathrm{~cm}$. by $20 \mathrm{~cm}$. opening in one end wall of the grid chamber, was $20.3 \mathrm{~cm}$. wide and $11.3 \mathrm{~cm}$. deep when the door separating the platform from the chamber was fully opened. A wooden chamber of the same dimensions as the shock chamber was used as a temporary retaining cage. Shocks were delivered by a Coulbourn Instruments solid state shocker (model E13-16) through the grid floor. All procedures, except placing the subject in or removing it from the apparatus, were automated with standard electromechanical programming equipment.

Procedure

Avoidance Training. One hundred and twenty randomly selected subjects were trained to a criterion of 10 consecutive avoidance responses. Subjects not meeting this criterion within 60 trials or those 
that received a total of over $60 \mathrm{sec}$. of shock exposure were discarded and replaced. An avoidance response was defined as getting completely onto the platform within $10 \mathrm{sec}$. of the start of a trial, signaled by the door opening, and remaining on the platform for $15 \mathrm{sec}$. After this 15 sec. safe period, the subject was automatically pushed off of the platform by the closing of the platform door. The subject then spent a variable $30 \mathrm{sec}$. intertrial interval on the grids before the onset of the next trial. No discriminative stimulus other than the door opening was used. The aversive stimulus was a scrambled shock registering $1.5 \mathrm{~mA}$. on the meter of the Coulbourn shocker.

The measures of acquisition of avoidance were: the number of trials to the criterion of 10 consecutive avoidance responses, the number of trials on which the subject was exposed to the shock and the total shock duration.

Twenty randomly assigned control subjects received no avoidance training. Instead, they were placed inside the avoidance apparatus with the platform door open for $15 \mathrm{~min}$, approximately the amount of time it took for the avoidance training. This "mock" avoidance training permitted control subjects familiarity with the apparatus comparable to that of the avoidance trained subjects, with the exception of the shock and avoidance contingency.

Treatment Delay. Thirty of the avoidance trained subjects were randomly assigned to receive the appropriate treatment at each of the delay intervals of 1 min., 1,7 or 49 days after avoidance training. Imnediately after the tenth consecutive avoidance response, each subject was returned to his home cage for the appropriate interval before proceeding to treatment. 
Treatment. Ten subjects from each treatment delay interval were randomly assigned to receive $45 \mathrm{~min}$. of RP. Each subject receiving this extended response prevention (ERP) was placed in the retaining cage for 1 min. followed immediately by being placed in the avoidance apparatus with the platform unavailable for $45 \mathrm{~min}$. (no shock present). Following ERP, each subject was placed in the retaining cage for $1 \mathrm{~min}$.

Ten subjects from each treatment delay interval were randomly assigned to receive $15 \mathrm{sec}$. of RP. Subjects receiving this short response prevention (SRP) were placed in the retaining cage for 45.75 min. and then in the avoidance apparatus with the platform unavailable for $15 \mathrm{sec}$. following the appropriate treatment delay interval. Subsequent to SRP, each subject was placed in the retaining cage for 1 $\min$.

Ten subjects from each treatment delay interval were randomly assigned to receive no response prevention (NRP). These subjects were placed in the retaining cage for $47 \mathrm{~min}$. after the appropriate treatment interval. To equate for handling, each subject was picked up and replaced in the retaining cage after $1 \mathrm{~min}$. and again after $46 \mathrm{~min}$. of the beginning of the treatment phase.

Ten of the control subjects who received mock avoidance training were randomly assigned to receive $45 \mathrm{~min}$. of RP at the $1 \mathrm{~min}$. treatment delay interval. The remaining 10 control subjects received $45 \mathrm{~min}$. of RP at the 49 day treatment delay interval.

Fear Assessment. Fear was measured as follows: Immediately after the final minute in the retaining cage each subject was placed on the platform of the avoidance apparatus with only $6.2 \mathrm{~cm}$. of the platform available. Data were then taken for $3600 \mathrm{sec}$. Two dependent measures 
were recorded. The first, approach latency, was defined as the duration, in seconds, before the subject completely departed from the platform and remained on the shock grids for at least three consecutive seconds. If the subject did not depart from the platform within one hour, a score of $3600 \mathrm{sec}$. was recorded. The second dependent measure was the total time in seconds that the subject spent on the shock grids during the $3600 \mathrm{sec}$. test period. 
RESULTS

Avoidance Training

The three acquisition variables were examined to determine whether ERP, NRP and SRP treatment groups received equivalent avoidance training. Tables 2,3 , and 4 show the means and standard deviations for total trials to the training criterion of 10 consecutive avoidances; the number of trials on which the subject was exposed to shock and the total duration of shock exposure, respectively. Since the analysis of variance is relatively insensitive to the assumption of homogeneity of variance, an alpha level of .Ol was selected for all $\underline{F} \max$ tests. For each of these variables $\underline{F} \max$ tests failed to reveal heterogeneity of variance (for total trials, $\underline{F} \max (12,9)=10.09$, n.s.; for number of shocked trials, $\underline{F} \max (12,9)=14.71$, n.s.; for shock duration, $\underline{F} \max (12,9)=$ 2.57 , n.s.). Three separate $3 \times 4$ analyses of variance failed to reveal differences among treatment groups for any of the three avoidance acquisition variables. (Appendices $A, B$, and $C$ contain the summary tables for the analyses of variance for total trials, shocked trials, and total shock received in reaching the avoidance training criterion, respectively. All other summary tables for analyses of variance are similarly shown in appendices).

Fear Assessment

Approach Latency without Control Groups. Because an incomplete $4 \times 4$ factorial design was employed in this study, excluding two cells of control subjects at the 1 and 7 day treatment delay intervals (see Table 1), initial analyses for each dependent variable were performed without data from control groups. Table 5 shows the means and standard deviations 
Table 2

Means and Standard Deviations of Total Trials

to 10 Consecutive Avoidances Acquisition Criterion

\begin{tabular}{|c|c|c|c|c|c|c|}
\hline \multirow[t]{2}{*}{$\begin{array}{l}\text { Treatment } \\
\text { Group }\end{array}$} & & \multicolumn{5}{|c|}{ Treatment Delay Interval in Days } \\
\hline & & 0 & 1 & 7 & 49 & Overall \\
\hline Short Response & M & 22.401 & 19.70 & 20.10 & 22.80 & 21.25 \\
\hline Prevention & SD & 4.65 & 7.62 & 10.52 & 10.05 & 8.32 \\
\hline No Response & M & 21.30 & 24.70 & 21.40 & 27.80 & 23.80 \\
\hline Prevention & SD & 8.59 & 9.03 & 8.53 & 14.76 & 10.50 \\
\hline Extended Response & M & 24.20 & 31.60 & 20.50 & 24.10 & 25.10 \\
\hline \multirow[t]{2}{*}{ Prevention } & SD & 10.93 & 10.77 & 5.02 & 11.42 & 10.34 \\
\hline & M & 22.63 & 25.33 & 20.67 & 24.90 & 23.38 \\
\hline Overall & SD & 8.26 & 10.20 & 8.07 & 12.00 & 9.82 \\
\hline
\end{tabular}

$l_{\text {Note: }} n$ per cell $=10$ 


\section{Table 3}

Means and Standard Deviations of Number of Shocked Trials to Avoidance Acquisition Criterion

\begin{tabular}{|c|c|c|c|c|c|c|}
\hline \multicolumn{2}{|c|}{$\begin{array}{l}\text { Treatment } \\
\text { Group }\end{array}$} & \multicolumn{5}{|c|}{ Treatment Delay Interval in Days } \\
\hline$\cdot$ & & 0 & 1 & 7 & 49 & Overall \\
\hline Short Response & $M$ & 7.501 & 5.70 & 6.70 & 6.70 & 6.65 \\
\hline Prevention & $\mathrm{SD}$ & 2.55 & 2.21 & 4.67 & 3.83 & 3.39 \\
\hline No Response & M & 7.20 & 8.40 & 7.40 & 9.90 & 8.22 \\
\hline Prevention & SD & 4.05 & 6.38 & 3.47 & 8.49 & 5.81 \\
\hline Extended Response & M & 8.40 & 10.90 & 6.70 & 7.30 & 8.32 \\
\hline Prevention & $\mathrm{SD}$ & 5.27 & 4.38 & 2.21 & 3.95 & 4.27 \\
\hline & M & 7.70 & 8.33 & 6.93 & 7.97 & 7.73 \\
\hline Overall & SD & 4.00 & 4.98 & 3.48 & 5.81 & 4.62 \\
\hline
\end{tabular}

$I_{\text {Note: }} n$ per cell $=10$ 
Table 4

Means and Standard Deviations of Total

Shocked Duration to Avoidance Acquisition Criterion

\begin{tabular}{|c|c|c|c|c|c|c|}
\hline \multicolumn{2}{|c|}{$\begin{array}{l}\text { Treatment } \\
\text { Group }\end{array}$} & \multicolumn{5}{|c|}{ Treatment Delay Interval in Days } \\
\hline & & 0 & 1 & 7 & 49 & Overall \\
\hline Short Response & M & 26.381 & 19.90 & 22.04 & 21.84 & 22.54 \\
\hline Prevention & SD & 8.86 & 12.04 & 14.19 & 9.57 & 11.18 \\
\hline No Response & M & 22.63 & 23.24 & 23.23 & 27.43 & 24.13 \\
\hline Prevention & SD & 10.96 & 9.10 & 7.91 & 14.07 & 10.52 \\
\hline Extended Response & M & 31.32 & 29.01 & 22.15 & 32.48 & 28.74 \\
\hline \multirow[t]{2}{*}{ Prevention } & $\mathrm{SD}$ & 13.11 & 12.69 & 11.93 & 11.46 & 12.51 \\
\hline & M & 26.78 & 24.05 & 22.47 & 27.25 & 25.14 \\
\hline Overall & SD & 11.32 & 11.63 & 11.24 & 12.25 & 11.64 \\
\hline
\end{tabular}

l $_{\text {Note: }} n$ per cell $=10$ 
for approach latency in seconds for the three avoidance trained treatment groups at each treatment delay interval. The time taken to depart from the platform was greatest for the subjects who received $15 \mathrm{sec}$. of RP with approach latencies for nontreated (NRP) subjects slightly lower. Subjects receiving $45 \mathrm{~min}$. of treatment approached the grids much more quickly. An examination of the approach latencies for each treatment delay interval (collapsed across treatment) suggests that the subjects who received treatment after 49 days took somewhat longer to depart from the platform than the subjects treated at the remaining three treatment delay intervals.

The standard deviations in Table 5 also suggest that the cell variances are heterogeneous. Results of an $\mathrm{E}$ max test found the heterogeneity to be severe $(\underline{F} \max (12,9)=426.28, \underline{p}<.01)$ so that a transformation of these data was warranted. A common log transformation (base 10$)$ was successful in removing the heterogeneity $(\underline{F} \max (12,9)=$ 6.75 , n.s.). The means and standard deviations of the transformed data are shown in Table 6.

A $3 \times 4$ analysis of variance (Appendix D) showed a significant treatment effect, $\underline{F}(2,108)=60.31, \underline{Q}<.01$ but no significant treatment delay or interaction effects. An Omega squared showed that the significant treatment ef fect accounted approximately for 50\% of the total variance $\left(\omega^{2}=.4933\right)$. A Newman-Kuels test determined that the ERP group approached significantly more quickly than either the NRP or SRP groups $(\mathrm{p}<.01)$ and that there was no significant difference between the latter groups.

Approach Latency with Control Groups. The mean approach latency for each treatment group including controls at each treatment delay interval 
Table 5

Means and Standard Deviations for Approach Latency (Sec.)

Treatment

Group
Treatment Delay Interval in Days

49

Overall

$\begin{array}{crrrrrr}\text { Short Response } & M & 1811.551 & 1092.35 & 858.25 & 2071.44 & 1458.40 \\ \text { Prevention } & \text { SD } & 1280.52 & 761.64 & 1166.70 & 1531.68 & 1273.90\end{array}$

No Response

$\begin{array}{llllll}M & 697.14 & 1574.22 & 1669.72 & 1707.82 & 1412.22\end{array}$

Prevention

$\begin{array}{llllll}\text { SD } & 1082.42 & 1578.06 & 1517.88 & 1631.88 & 1472.59\end{array}$

Extended Resp
Prevention

$M$

M

110.15

101.45

98.92

89.27

99.95

SD $\quad 116.32$

136.38

79.04

122.81

111.33

M

872.95

922.67

875.6

1289.51

990.19

Overall

SD $\quad 1179.73$

1160.82

1250.99

1525.50

1283.18

lNote: $n$ per cell $=10$ 
Table 6

Means and Standard Deviations of Log Transformed

Scale for Approach Latency

Treatment
Group
Treatment Delay Interval in Days

0

1

7

49

Overall

\begin{tabular}{lrlllll}
\hline Short Response & $M$ & 3.141 & 2.95 & 2.67 & 3.12 & 2.97 \\
Prevention & SD & 0.36 & 0.29 & 0.45 & 0.52 & 0.44
\end{tabular}

No Response

M

2.48

2.83

2.98

2.88

2.79

Prevention

SD

0.64

0.73

0.53

0.76

0.67

Extended Response $M$

1.83

1.68

1.83

1.69

1.76

Prevention

SD

0.46

0.55

0.44

0.48

0.47

M

2.48

2.49

2.50

2.57

2.51

Overall

SD

0.73

0.79

0.68

0.86

0.76

$l_{\text {Note: }} n$ per cell $=10$ 
is found in Figure 1. Table 7 shows the means and standard deviations for approach latency in seconds for all treatment groups including controls at the $1 \mathrm{~min}$. and 49 day treatment delay intervals. It is evident from both the figure and the table that subjects in the control group at each treatment delay interval approached the shock grids almost immediately, approximately 4 times more quickly than ERP subjects.

Table 7 also suggests that the cell variances are severely heterogeneous. F max tests for the data at each treatment delay interval showed this to be the case $(F \max (4,9)=6354.20, \mathrm{~g} \leqslant .01$ and $\underline{F} \max$ $(4,9)=6462.60, \underline{p}<.01$ for treatment delays of 1 min. and 49 days, respectively). The common $\log$ transformation (base 10) was successful in removing the heterogeneity of each $(\underline{F} \max (4,9)=5.62$, n.s. and $\underline{F} \max$ $(4,9)=6.72$, n.s. for treatment delays of 1 min. and 49 days respectively). Table 8 shows the means and standard deviations of these transformed data.

At the 1 min. treatment delay interval a one way analysis of variance on the transformed data (Appendix E) showed the four treatment groups to differ significantly in approach latency, $\underline{F}(3,36)=30.16$ $\mathrm{Q}^{<} .01$ with $68 \%$ of the variance accounted for $\left(\omega^{2}=.6829\right)$. A Newman-Kuels test showed that each group differed from all others at $\mathrm{g}<.01$ except the control and ERP groups which differed at $\mathrm{g}<.05$. At the 49 day treatment delay interval a one way analysis of variance on the transformed data (Appendix F) showed the treatment groups to differ significantly, $\underline{F}(3,36)=28.23, \underline{\mathrm{g}}<.01$, with $67 \%$ of the variance accounted for $\left(\omega^{2}=.6713\right)$. A Newman-Kuels test showed that the control and ERP groups differed from the NRP and SPP ( $\mathrm{p}<.01$ ) but that there were no differences between either the control or ERP groups or the NRP and 
Figure Caption

Figure 1. Mean approach latency for treatment groups at each treatment delay interval. 
MEAN APPROACH LATENCY (SEC.)

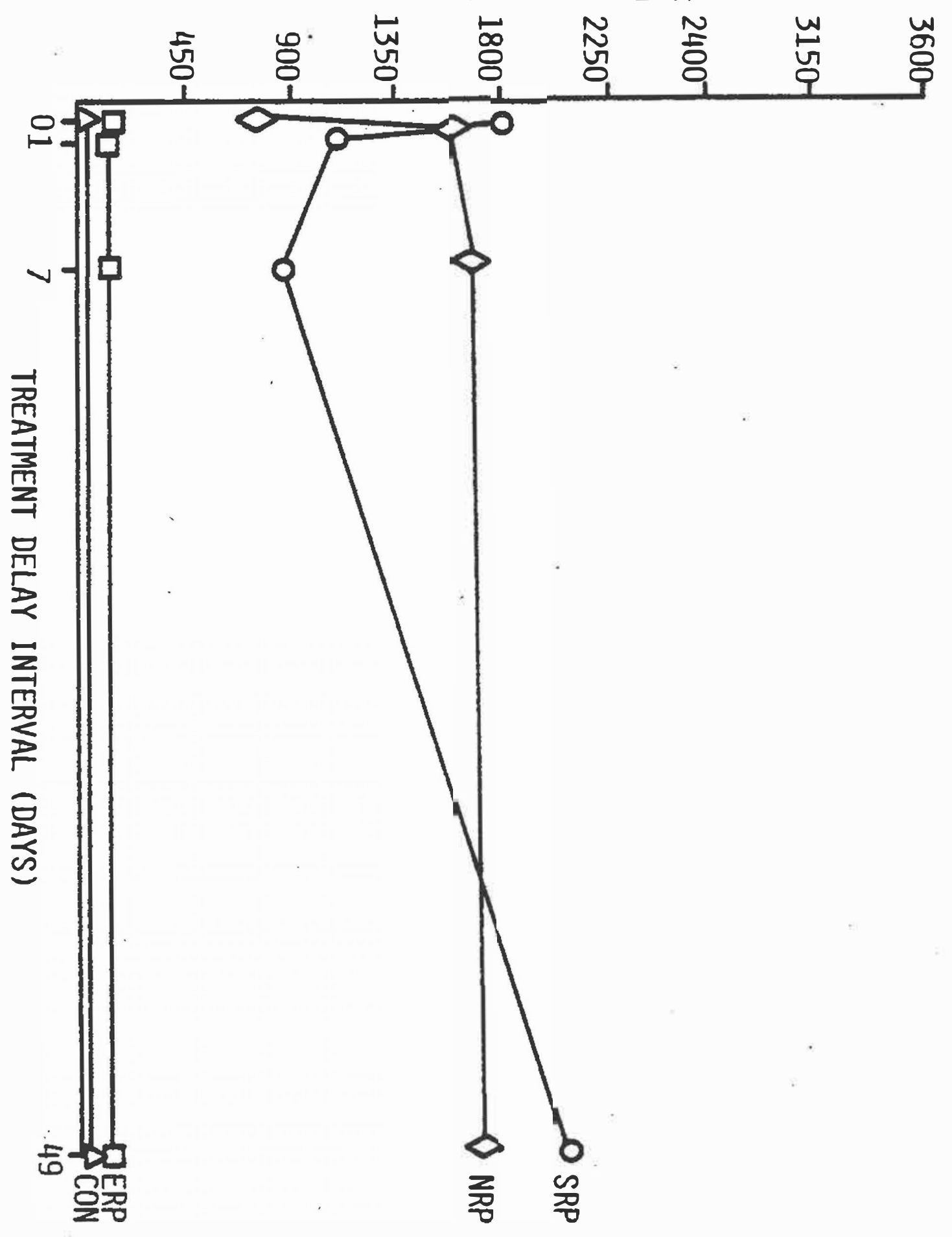


Table 7

Means and Standard Deviations for Approach Latency (sec.)

at Treatment Delay Intervals Including Control Groups

Treatment

Group

Treatment Delay Interval in Days

$\begin{array}{lll}0 & & \\ 0 & \text { Overall }\end{array}$

Short Response

1811.551

2071.44

1941.49

Prevention

$S D$

1280.52

1531.68

1380.50

No Response

M

697.14

1707.82

1202.48

Prevention

SD

1082.42

1631.88

1444.03

Extended Response

M

110.15

89.27

99.71

Prevention

SD

116.32

122.81

116.91

M

24.27

22.26

23.26

Control

SD

16.06

20.30

17.85

Overall

M

660.78

972.70

816.74

SD

1083.27

1428.06

1269.14

$l_{\text {Note: }} \mathrm{n}$ per cell $=10$ 
Table 8

Means and Standard Deviations for Log Transformed Scale for Approach Latency at Treatment Delay Intervals Including Control Groups

\section{Treatment \\ Group}

Treatment Delay Interval in Days

49

Overall

Short Response

M

3.141

3.12

3.13

Prevention

SD

0.36

0.52

0.43

No Response

M

2.48

2.88

2.68

Prevention

SD

0.64

0.76

0.71

Extended Response

1.83

1.69

1.76

Prevention

SD

0.46

0.48

0.46

M

1.32

1.26

1.29

Control

SD

0.27

0.29

0.28

Overall

M

2.19

2.24

2.22

SD

0.82

0.95

0.88

$l_{\text {Note: }} n$ per cell $=10$ 
SRP groups.

A one way analysis of variance (Appendix $G$ ) showed that the two control groups did not differ in approach latency $(F(1,18)<1.0)$. Time on Gids Mithout Control Groups. Table 9 shows the means and standard deviations for the total time in seconds that the subjects spent on the shock grids during the $3600 \mathrm{sec}$. test period for the three avoidance trained groups at each treatment delay interval, subjects receiving the extended treatment demonstrated the most grid time in testing and spent approximately three times longer on the grids than the SPP or NRP subjects. The latter groups did not differ significantly. An examination of time spent on the grids at each treatment delay interval (collapsed across treatments) yielded no apparent pattern, with subjects treated at 49 days after training showing the least time on the grids and subjects treated at seven days exhibiting the most.

Tests for heterogeneity of variance on these data proved nonsignificant $(\underline{F} \max (12,9)=5.41$, n.s.). A $3 \times 4$ analysis of variance (Appendix $H$ ) yielded a significant treatment effect $(\underline{F}(2,108)$ $=41.82, \mathrm{Q}<.01$ ) but no significant treatment delay or interaction effects. An Omega squared showed that the treatment effect accounted for $40 \%$ of the total variance $\left(\omega^{2}=.4049\right)$. A Newman-Kuels test demonstrated that the EPP group spent significantly more time on the grids than did either the NRP or SRP groups $(p<.01)$. There was no significant difference between the NRP and SRP groups.

Time on Grids with Control Groups. Figure 2 shows the mean time spent on the grids for each treatment group including the controls at each treatment delay interval. Table io shows the means and standard deviations for time spent on the grids for all treatment groups at the 
Table 9

Means and Standard Deviations for Total Grid Time (sec.)

Treatment Group
Treatment Delay Interval in Days

$\begin{array}{lllll}0 & 1 & 7 & 49 & \text { Overall }\end{array}$

\begin{tabular}{|c|c|c|c|c|c|c|}
\hline Short Response & $M$ & 747.821 & 1099.12 - & 1459.06 & 528.21 & 958.55 \\
\hline Prevention & $\mathrm{SD}$ & 1146.00 & 1391.77 & 1554.49 & 1015.83 & 1293.84 \\
\hline No Response & $M$ & 1483.13 & 509.08 & 1525.63 & 841.60 & 1089.86 \\
\hline Prevention & $S D$ & 1286.54 & 685.49 & 1531.56 & 1358.72 & 1283.89 \\
\hline Extended Response & $M$ & 3142.12 & 3131.40 & 3080.99 & 3062.20 & 3104.17 \\
\hline \multirow[t]{2}{*}{ Prevention } & $\mathrm{SD}$ & 1105.02 & 1025.18 & 866.72 & 746.97 & 909.72 \\
\hline & $M$ & 1791.02 & 1579.87 & 2021.89 & 1477.34 & 1717.53 \\
\hline Overall & $S D$ & 1528.93 & 1542.18 & 1513.93 & 1543.53 & 1527.24 \\
\hline
\end{tabular}

l ${ }_{\text {Note: }} n$ per cell $=10$ 
Figure Caption

Figure 2. Mean time on grids for treatment groups at each treatment delay interval. 


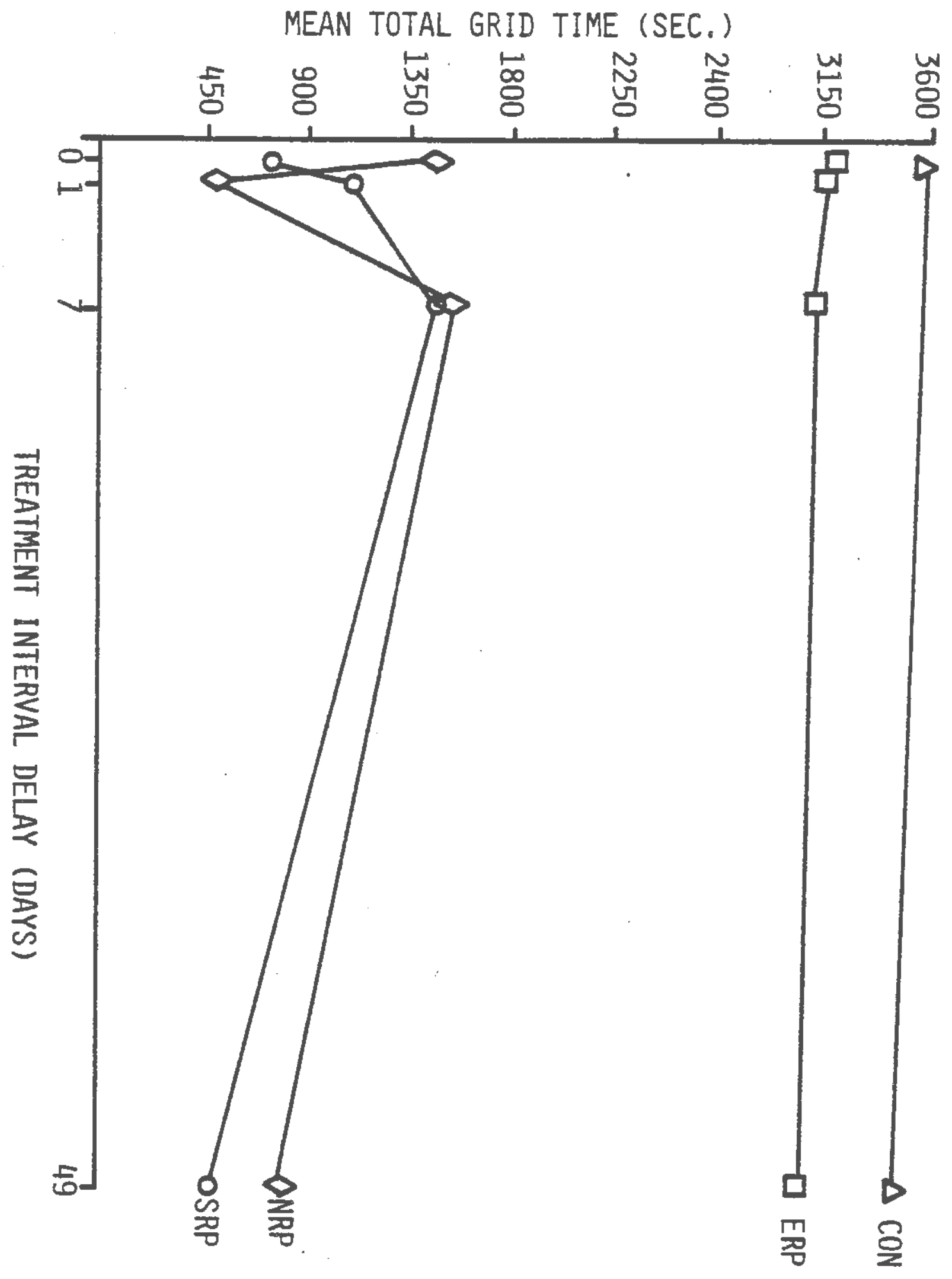


$1 \mathrm{~min}$. and 49 day treatment delay intervals. It is evident from both the figure and the table that the control subjects spent all but a few seconds of the $3600 \mathrm{sec}$. test period on the grids, logging more grid time than even the ERP subjects.

Table 10 also suggests that, with the addition of the relatively low variances on the control groups, the cell variances are heterogeneous. $F$ max tests for the data at each treatment delay interval showed this to be true; the data at the $1 \mathrm{~min}$. interval showed severe heterogeneity ( $\underline{F} \max$ $(4,9)=3148.90, \mathrm{p}<.01)$ and the data at the 49 day interval showeo moderate heterogeneity $(\underline{F} \max (4,9)=187.88, \underline{p}<.01)$. Because the pattern of scores within each treatment delay interval indicated that the distribution was approximately rectangular, an arcsine transformation (arcsine $[(x+10) / 3600])$ was chosen. Edwards (1972) has shown this transformation to be effective in both reducing variance and making the data more normally distributed. Means and standard deviations of these transformed data are shown in Table 11. The transformation had the effect of reducing heterogeneity for the data in both treatment delay intervals ( $F$ $\max (4,9)=66.20, \underline{\mathrm{p}}<.01$ and $\underline{\mathrm{F}} \max (4,9)=14.02, \mathrm{p}<.01$ for the $\mathrm{l}$ minute and 49 day intervals, respectively). While mild heterogeneity of variance still existed it has been shown that analysis of variance is robust to moderate violations of homogeneity of variance especially when cell sizes are equal (Boneau, 1960; Glass, Peckham, \& Saunders, 1972; Ransey, 1980).

At the $1 \mathrm{~min}$. treatment delay interval a one way analysis of variance on the transformed data (Appendix I) showed that the treatment groups spent significantly different amounts of time on the grids during the test period $(\underline{F}(3,36)=27.43, \underline{p}<.01)$. This accounted for $66 \%$ of the variance 
$\left(\omega^{2}=.6647\right)$. A Newman-Kuels test showed that the control and ERP groups each differed from the NRP and SRP groups $(p<.01)$ but that there were no significant differences within either pair.

A one way analysis of variance on the transformed data at the 49 day treatment delay interval (Appendix I) similarily showed that the treatment groups differed significantly, $\underline{F}(3,36)=27.56, \underline{\underline{p}}<.01$, which accounted for $67 \%$ of the variance $\left(\omega^{2}=.6658\right)$. A Newman-Kuels test showed that the

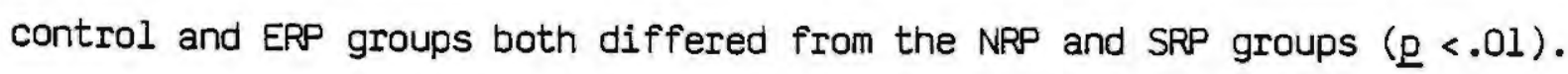
There were no differences between the former or latter pairs of groups. (Because the mild heterogeneity of variance remained in these data, nonparametric analyses were also performed. Results from these analyses were practically identical to the results using transformed data and parametric tests and are found in Appendix $K$ ).

$A$ one way analysis of variance (Appendix $L$ ) showed that the two control groups did not differ in the amount of time that each spent on the grids, $\underline{F}$ $(1,18)=4.21$, n.s.

The Relationship Between Approach Latency and Time on Grids. A Pearson correlation analysis was performed between the two transformed fear assessment variables in order to determine the extent to which approach latency and the amount of time spent on the grids measured the same fear construct. The result showed a significant correlation with $I=-.80, \underline{p}<.01$. 
Table 10

Menas and Standard Deviations for Total Grid Time (in sec.) at Treatment Delay Intervals Including Control Groups

\section{Treatment Group}

Treatment Delay Interval in Days

0

Overall

Short Response 638.01

Prevention

No Response

Prevention

Extended Response

Prevention

Control

Overall
747.821

1146.00

1483.13

1105.02

3142.12

1286.54

3569.67

SD

22.93

2235.68

SD

1531.91
1981.27

2108.47
1560.88

1598.51

2108.47
1560.88

528.21

1015.83

1059.99

1162.36

918.90

3102.16

1329.22

3531.37

80.34

99.20

$I_{\text {Note: }} n$ per cell $=10$ 
Table 11

Means and Standard Deviations for Arcsine Transformed Scale for Total Grid Time at Treatment Delay Intervals Including Control Groups

\section{Treatment \\ Group}

Treatment Delay Interval in Days

49

Overall
Short Response

Prevention

No Response

Prevention

Extended Response

Prevention

\begin{tabular}{lrlll} 
& $M$ & 1.48 & 1.38 & 1.43 \\
Control & SD & 0.05 & 0.14 & 0.11 \\
Overall & $M$ & 0.85 & 0.74 & 0.80 \\
& SD & 0.62 & 0.63 & 0.62 \\
\hline
\end{tabular}

0

0.231

0.16

0.20

SD

0.36

0.31

0.33

$M$

0.47

0.30

0.39

SD

0.43

0.52

0.48

$M$

1.22

1.12

1.17

SD

$0.44^{\circ}$

0.36

0.39

$l_{\text {Note: }} n$ per cell $=10$ 


\section{DISCUSSION}

The hypothesis that extended RP would facilitate the reduction of fear to a CS was supported. Subjects in the ERP group approached the shock chamber sooner and spent more time on the shock grids during the one hour test period than the subjects in the NRP group. This result is consistent with the majority of findings where extended RP was employed and fear was assessed by either persistence of avoidance (Baum, 1968a \& b; Berman, \& Katzev, 1972; Corriveau, 1978; Mineka, \& Gino, 1979a; Reynierse, \& Wiff, 1973; Schieff, et. al., 1972) or the CER assessment techniques (Monti, \& Smith, 1976; Mineka, \& Gino, 1979b; Starr, \& Mineka, 1977). It is also consistent with results from studies which used the approach assessment methodologies (Bersh, \& Paynter, 1972; Corriveau, 1978; Corriveau, \& Smith, 1978; Corriveau, et. al., 1978; Mineka, et. al., 1981; Neill, 1980; Neill, et. al., Note 3; Neill, et. al., Note 4).

It is interesting to note that the ERP subjects in this study approached the grids as quickly and spent a statistically equivalent amount of time on the grids as the nonavoidance trained control subjects, except at the one min. treatment delay interval where the control group approached the grids significantly more quickly. These results indicate that the fear reduction was essentially complete in this study, i.e., the ERP subjects showed the same lack of fear of the grid chamber after treatment as those subjects never receiving shock. It should be noted that the ERP groups show a pattern of more fear than the control groups (see figures 1 and 2 ) but that the statistical equivalence of these groups conflicts with most other approach measure based research which reports incomplete fear reduction after extended RP. (Corriveau, \& 
Smith, 1978; Coulter, et. al., 1969; Linton, et. al., 1970; Neill, 1980; Neill, et. al., Note 3). Because the incomplete fear reduction in ERP subjects occurred only at the one min. treatment delay interval it might be suggested that delayed treatment has a greater ability to reduce fear. This possibility will be discussed below.

The prediction that subjects receiving brief exposure to the CS would show an overall increase in fear compared to untreated subjects was not supported. There were no significant differences between the SRP and NRP groups in the amount of time each took to approach the grid chamber or in the amount of time spent on the grids. These results indicate that the amount of fear exhibited by subjects receiving short exposure to the CS was no greater than that exhibited by subjects receiving no treatment. This finding conflicts with the majority of research employing short durations of RP in which significant fear enhancement has been found after brief CS exposure (Gordon, et. al., 1979; Linton, et. al., 1970; Rohrbaugh, \& Riccio, 1970; Rohrbaugh, et. al., 1972).

While an overall fear enhancement effect was not demonstrated, there was evidence of greater fear in the SRP than the NRP groups at the one min. treatment delay interval. At this interval subjects receiving the short CS exposure took significantly longer to approach the grids than the NRP subjects. This finding would be consistent with some research showing fear enhancement when fear was measured immediately after treatment (Rohrbaugh, et. al., 1972) but conflict with other results showing no enhancement at immediate retention intervals (Rohrbaugh, \& Riccio, 1970).

It should be noted that it was only at the one min. treatment delay interval that both fear enhancement (the SPP group showing longer 
approach latencies than the NRP group) and incomplete fear reduction (the ERP group showing longer approach latencies than the NRP group) were demonstrated. No significant differences were found in approach latencies between the SRP and NRP groups at treatment delays of 1,7 , or 49 days and the ERP subjects approached the grids as quickly as control subjects at the 49 day treatment delay interval. These findings suggest the possibility that delays in treatment eliminate the enhancement effect resulting from brief CS exposure and the incomplete reduction of fear from extended RP. That is, delayed CS exposure of either duration may result in lower levels of fear than immediate exposure.

This interpretation does not seem likely for several reasons. First, both fear enhancement and complete fear reduction were found with only one dependent variable, approach latency, and were not shown by the other dependent variable, total grid time. Previous research by Corriveau, \& Smith (1978) and Mineka, et. al., (1981) has shown that approach latency and total grid time are highly negatively correlated and the Pearson $I=-.80$ in the present study supports this. Further, the results of Mineka, et. al. suggest that total grid time may be a more sensitive measure of fear following a wide range of RP durations. It is unclear why fear enhancement and incomplete fear reduction should be seen with only approach latency and not time on grids although it should be noted that most research showing these effects employed only approach latency. Second, there is no indication that a significant decrease in fear occurred for the SRP or ERP groups on either dependent variable. That is, there is a lack of significant differences among the SRP groups over the four treatment delay intervals and a similar lack of differences for the ERP groups. Third, delayed exposure to a brief CS has been shown to 
be an effective fear enhancement procedure (Gordon, et. al., 1979). Fourth, there is evidence to suggest that the differences between the SRP and NRP groups in this study may not be due to an enhancement of fear shown by the former group but to the presence of the Kamin effect exhibited by the latter.

Kamin (1957) discovered that subjects trained to actively avoid a CS exhibited performance decrements if training was interrupted and then resumed after one hour. These decrements were not present if the interruption lasted for 24 hours. The phenomenon has been called the Kamin effect (for a reveiw of the Kamin effect see Brush, 1971). Pinel, \& Cooper (1966) have proposed a motivational explanation of this decrement, suggesting that fear is decreased roughly an hour after initial exposure to aversive situations. Because of the reduction of fear the subject does not respond as readily when the avoidance contingencies are reinstituted. Spear (1973) has given a memory based interpretation to the phenomenon, proposing that after an hour interval hormonal stimuli present at the time of original stress exposure are no longer avilable to the subject. The lack of these stimuli leads to a memory deficit of the original avoidance contingencies. The memory deficit then accounts for the decreased avoidance responding. It should be noted that Spear's proposal of a deficit in recalling the original avoidance contingencies can be used to explain Pinel, \& Cooper's fear deficit hypothesis if one adopts Rescorla, \& Solomon's (1967) definition of fear as a subject's internal representation of the avoidance contingencies.

The data in the present experiment suggest the posibility of a weak Kamin effect. Table 5 shows the mean approach latency for the NRP group 
at the 1 min. treatment delay interval to be substantially less than that exhibited by the NRP group at the 1 day treatment delay interval. This difference may be due to the amount of time spent between avoidance training and fear testing for each group. The former subjects each spent $1 \mathrm{~min}$. in his home cage and then $47 \mathrm{~min}$. in the retaining cage immediately after avoidance training and then were replaced in the apparatus for fear testing. This delay of almost 1 hour, as opposed to a 24 hour, $47 \mathrm{~min}$. delay for the latter group, may account for the apparent relative lack of fear in the 1 minute treatment delay interval group. while the variance in each group is high and the difference in approach latencies is not statistically significant, pilot experiments by vyse (Note 6 ) have shown a possible Kamin effect using a 1 hour delay (instead of $45 \mathrm{~min}$. ) and a slightly stronger aversive stimulus (1.7 $\mathrm{mA}$ instead of $1.5 \mathrm{~mA}$ of shock). If the Kamin effect was responsible for the decrement in this experiment, it should be noted that the brief exposure to the CS in the SRP group was sufficient to reactivate the memory of the avoidance contingencies (fear) as had been demonstrated by Arisman, \& waller (1971). Why then was fear enhancement resulting from brief exposure to the CS not demonstrated in this experiment? One possibility is that the level of fear demonstrated by the NRP group was at the ceiling of the measurement scale and this precluded the demonstration of an increased level of fear by the SRP group. However, since the mean approach latency for the NRP group is approximately one half the possible $3600 \mathrm{sec}$. ano the mean time spent on the grids is substantially larger than zero (i.e., about 1100 sec.) this possibility does not seem likely. A more plausible explanation is that the parameters employed to induce increased fear in 
this experiment were insufficient to do so. while both Gordon, et. al., (1979) and Rohrbaugh, et. al., (1972) were able to demonstrate enhancement after a $15 \mathrm{sec}$. CS exposure, a series of experiments by Rohrbaugh, \& Riccio (1970) suggest that the enhancement effect can be somewhat elusive. In their first study no enhancement of fear was demonstrated after a $30 \mathrm{sec}$. CS exposure while $5 \mathrm{~min}$. of RP increased fear only marginally. However, by employing younger subjects and a weaker shock level in their second experiment, they were able to show a robust enhancement of fear after both 30 and $60 \mathrm{sec}$. of $\mathrm{RP}$ and no enhancement at five min. of CS exposure. This suggests that the ability to obtain enhancement is subject not only to the length of the CS exposure but also to other parameters employed in the study. While the present study employed a brief duration of RP that had been shown to be effective in increasing fear by Gordon, et. al., and Rohrbaugh, et. al., these latter experiments used different types and levels of shock, apparatuses, training criteria, and measures of fear. Thus, with the present procedures an increase in the amount of CS exposure may have produced the enhancement effect. Still, it is interesting to note that the present results show that fear enhancement is not a necessary result of brief CS exposure.

Perhaps the most interesting results of this study come from the investigation of the effects of delaying extended periods of $R P$ on fear reduction. The prediction was that the amount of fear demonstrated by subjects receiving treatment at different treatment delay intervals would be equal to that exhibited by subjects treated immediately after training, provided that the memory of the avoidance contingencies did not decrease. However, if subjects showed forgetting of the contingencies as 
was demonstrated by Gordon, et. al., (1979) it was predicted that RP would serve as a reactivation procedure and the memory of the avoidance contingencies would be reinstated. This would result in an increase in fear exhibited by the SRP group and possibly also by the ERP groups if the duration of RP was not sufficient to reduce fear. Further, as Spear, et. al. (1980) showed reactivation procedures to produce stronger memory of'training after extended delays, it was predicted that the amount of fear demonstrated after delayed CS exposure would be greater than after immediate treatment.

Results from the present experiment clearly support the first prediction. The lack of significant treatment delay interval or treatment by treatment delay interval effects for both dependent variables suggests that the outcome of delayed treatment was the same as the outcome of immediate treatment. It should be emphasized that the amount of fear exhibited by the NRP subjects was the same across all treatment delay intervals. No significant decrease in approach latency or increase in time spent on the shock grids in these groups demonstrated that the memory of the avoidance contingencies did not decrease over 49 days. This finding supports those of Campbell, \& Campbell (1962), Neill (1980) and Neill, Cottrill, \& Smith (Note 3) while conflicting with those of Gordon, et. al. (1979). More importantly, the ability of extended RP to significantly reduce fear was demonstrated not only when treatment was instituted immediately after training but also when substantial delays intervened. The ERP subjects demonstrated significantly shorter approach latencies and greater time spent on the shock grids than the untreated subjects at each treatment delay interval and, perhaps more significantly, showed a remarkable uniformity on both dependent variables 
from one interval to the next. For example, the range of the mean approach latencies was only 20 seconds across the four intervals. This latter finding suggests that the amount of fear reduction resulting from extended RP was consistent no matter when the treatment occurred at least under conditions where the memory of the avoidance contingencies remained strong. Further, as has been discussed, the lack of significant differences between the ERP and control subjects at the 1 min. and 49 day treatment delay intervals suggest that fear reduction was essentially complete not only when treatment came immediately but also when it was delayed for 49 days.

While extreme caution and care must be exercised in discussing the implications of subhuman analogue research for clinical settings, the present study may be useful in suggesting further applied research in implosion therapy. First, this study contradicts previous findings by showing that fear reduction in analogue settings can be virtually complete. While evidence of fear reduction following implosion therapy has been reported (Baum, \& Poser, 1971; Hogan, \& Kirchner, 1967, 1968; Stampfl, \& Levis, 1967), incomplete treatment effects have also been cited (Rachman, 1966; Rachman, Marks, \& Hodgoon, 1973). It appears that, as in analogue research, a number of parameters are important in determining the degree of fear reduction after therapy, including the amount of original fear and the duration of treatment. While some authors question whether implosion therapy is an efficient fear reducing treatment (Morganstern, 1973, 1974), the present analogue results are encouraging .

Just as extended RP and implosion have been shown to reduce fear in analogue research and clinical settings respectively, so, too, have brief 
CS exposures been shown to enhance fear in each situation. Clinical enhancement of fear after brief periods of therapy has been demonstrated by Miller, \& Levis (1971) and Stone, \& Borkovec (1975). However, the present results suggest that an increase in fear is not a necessary result of brief RP and that possible analogous results may be found in clinical situations depending, again, on the parameters involved. While part of the criticism of implosion therapy is that clients experience increased fear during initial portions of the therapy session (Morganstern, 1973), the present analogue results suggest that this may not occur in every situation. Clearly, further research on the course of fear change over the entire duration of therapy would be beneficial.

The third and most important finding of this study, that extended RP is as effective in reducing fear after long delays as when applied immediately after fear training, may also be relevant to implosion therapy. It has been assumed that delays in treatment of clients with long standing phobias would result in increased anxiety (Eysenck, 1968, 1976) and therefore, more rigorious treatment would be required. The present research suggests that this may not necessarily be the case. If clinical research confirms the findings that treatment delays produce no significant decrement in the efficacy of implosion therapy, then clients with multiple problems may benefit more by the immediate treatment of problems other than their phobias. 
Reference Notes

1. Corriveau, D. USC intensity and safety testing behavior following response prevention. Paper presented at the meeting of the Eastern Psychological Association, Boston, April, 1977.

2. Neill, S. A., Corriveau, D., \& Smith, N. F. The persistence of fear reduction resulting from response prevention. Paper presented at the Eastern Psychological Association, Hartford, April, 1980.

3. Neill, S. A., Cottrill, S. D., and Smith, N. F. Retention of fear and response prevention effects over 30 days in rats. To be presented at the annual meeting of the Eastern Psychological Association, Baltimore, 1982.

4. Neill, S. A., Smith, N. F., \& Riccitelli, A. The presence of apparatus cues versus discriminative stimuli in the effectiveness of response prevention. Paper presented at the Eastern Psychological Association, New York, April, 1981.

5. Vuono, P. J., Neill, S. A., \& Smith, N. F. The interaction of anxiolytic and anxiogenic drugs with response prevention in rats. To be presented at the annual meeting of the Eastern Psychological Association, Baltimore, 1982.

6. Vyse, S. Personal Communication, March 1982. 


\section{REFERENCES}

Anisman, H., \& haller, T. G. Effects of conflicting response requirements and shock-compartment confinement on the Kamin effect in rats. Journal of Comparative and Physiological Psychology, 1971, 77, 240-244. Baum, M. Extinction of an avoidance response following response prevention: Some parametric investigations. Canadian Journal of Psychology, $1969,23,1-10$. (a)

Baum, M. Extinction of an avoidance response motivated by intense fear: Social facilitation of the action of response prevention (flooding) in rats. Behaviour Research and Therapy, 1969, 7, 57-62.

Baum, M. Extinction of avoidance responding through response prevention (flooding). Psychological Bulletin, 1970, 74, 276-282.

Baum, M., \& Poser, E. Comparison of flooding procedures in animals and man. Behaviour Research and Therapy, 1971, 9, 249-251.

Benline, T., \& Simmel, E. Effects of blocking of avoidance response on the elimination of the conditioned fear response. Psychonomic Science, $1967, \underline{8}, 357-358$.

Berman, J., \& Katzev, R. Factors in the rapid elimination of avoidance behaviour. Behaviour Research and Therapy, 1972, 10, 247-256. Bersh, P., \& Paynter, w. Pavlovian extinction of avoidance responses under curare. Journal of Comparative and Physiological Psychology, $1972,78,255-259$.

Bolles, R. Species-specific defense reaction and avoidance learning. Psychological Review, 1970, 77, 32-48.

Boneau, C. A. The effects of violations of assumptions underlying the $\underline{t}$ test. Psychological Bulletin, 1960, 57, 49-64. 
Brush, F. R. Retention of aversively motivated behavior. In F. R. Brush (Ed.), Aversive conditioning and learning, New York: Academic Press, 1971.

Campbell, B. A., \& Campbell, E. H. Retention and extinction of learned fear in infant and adult rats. Journal of Comparative and Physiological Psychology, 1962, 55, 1-8.

Campbell, B. A., \& Jaynes, J. Reinstatement. Psychological Review, 1966, 73, $478-480$.

Corriveau, D. A direct comparison of three fear assessment techniques. Unpublished doctoral dissertation, University of Rhode Island, 1978. Corriveau, D., Contildes, K., \& Smith, N. Social facilitation following response prevention in the rat. Psychological Reports, 1978, 43, 127-133.

Corriveau, D., \& Smith, N. Fear reduction and safety testing behavior following response prevention: A multivariate analysis. Jaurnal of Experimental Psychology: General, 1978, 107, 145-158.

Coulter, S., Riccio, D., \& Page, H. Effects of blocking an instrumental avoidance response. Journal of Comparative and Physiological

Psychology, 1969, 68, 377-381.

Edwards, E. L. Experimental design in psychological research (fourth ed.). Holt, Rinehart, \& Winston, Inc., New York, 1972.

Eysenck, H. J. A theory of the incubation of anxiety/fear responses. Behaviour Research and Therapy, 1968, 6, 309-321. Eysenck, H. J. The learning theory model of neurosis: A new approach. Behaviour Research and Therapy, 1976, 14, 251-267. 
Glass, G., Peckham, P., \& Sanders, J. Consequences of failure to meet assumptions underlying the fixed effects analysis of variance and covariance. Review of Educational Research, 1972, 42, 237-288. Gordon, W., Smith, G., \& Katz, D. Dual effects of response blocking following avoidance learning. Behaviour Research and Therapy, 1979, 17, $479-487$.

Herrnstein, R. Method and theory in the study of avoidance. Psychological Review, 1969, 76, 49-69.

Hilgard, E. L., \& Humphreys, L. G. The retention of conditioned discrimination in man. Journal of General Psychology, 1938, 19, 111-125. (b) Hogan, R., \& Kirchner, J. Preliminary report of the extinction of learned fears via short-term implosion therapy. Journal of Abnormal Psychology, 1967, 72, 106-109.

Hogạn, R., \& Kirchner, J. Implosive, eclectic verbal and bibliotherapy in the treatment of fears of snakes. Behaviour Research and Therapy, $1968, \underline{6}, 176-181$.

Kamin, L. J. The retention of an incompletely learned avoidance response. Journal of Comparative and Physiological Psychology, 1957, 50, 457-460. Kamin, L. J., Brimmer, C., \& Black, A. Conditioned suppression as a monitor of fear of the CS in the course of avoidance training. Journal of Comparative and Physiological Psychology, 1963, 56, 497-501. Kirby, R. Acquisition, extinction, and retention of an active avoidance response in rats as a function of age. Journal of Comparative and Physiological Psychology, 1963, 56, 158-162. 
Kline, S. B., \& Spear, N. E. Influence of age on short-term retention of active-avoidance learning in rats. Journal of Comparative and Physiological Psychology, 1969, 69, 583-589.

Kline, S. B., \& Spear, N. E. Reactivation of avoidance-learning memory in the rat after intermediate retention invervals. Journal of Comparative and Physiological Psychology, 1970, 72, 498-504.

Leitenberg, H. Behavioral approaches to treatment of neuroses. In $\mathrm{H}$. Leitenberg (Ed.), Handbook of behavior modification and behavior therapy. Englewood Cliffs, N.J., Prentice Hall.

Levis, D. Implosive therapy: The subhuman analogue, the strategy, and the technique. V.A. Publication, Battle Creek, Michigan, 1966. Linton, J., Riccio, D., Rohrbaugh, M., \& Page, H. The effects of blocking an instrumental avoidance response: Fear reduction or enhancement? Behaviour Research and Therapy, 1970, 8 267-272.

Marquis, D., \& Hilgard, E. Conditioned lid responses to light in dogs after removal of the visual cortex. Journal of Comparative Psychology, $1936, \underline{22}, 157-158$.

Miller, B. V., \& Levis, D. The effects of varying short visual exposure times to a phobic test stimulus on subsequent avoidance behavior. Behaviour Research and Therapy, 1971, ㅁ, 17-21.

Mineka, S. The role of fear in theories of avoidance learning, flooding and extinction. Psychological Bulletin, 1979, 86, 985-1010.

Mineka, S., \& Gino, A. Some further tests of the brief confinement effect and the SSDR account of flooding. Learning and Motivation, 1979, 10, 98-115. (a) 
Mineka, S., \& Gino, A. Dissociative effects of different types and amounts of nonreinforced CS exposure on avoidance extinction and the CER. Learning and Motivation, 1979, 10, 141-160.

Mineka, S., \& Gino, A. Dissociation between conditioned emotional response and extended avoidance performance. Learning and Motivation, $1980, \underline{11}, 476-502$.

Mineka, S., Miller, S., Gino, A., \& Giencke, L. Dissociation effects of flooding on a multivariate assessment of fear reduction and on jump-up avoidance extinction. Learning and Motivation, 1981, 12, $435-461$.

Monti, P., \& Smith, N. Residual fear of the conditioned stimulus as a function of response prevention after avoidance or classical defensive conditioning in the rat. Journal of Experimental Psychology, 1976, $105,148-162$.

Morganstern, K. Implosion therapy and flooding procedures: A critical review. Psychological Bulletin, 1973, 79, 318-334. Morganstern, K. Issues in implosive ther py: Reply to Levis. Psychological Bulletin, 1974, 81, 380-382. Mowrer, 0. H. Anxiety reduction and learning. Journal of Experimental Psychology, 1940, 27, 497-516.

Mowrer, O. H. Learning theories and personality dynamics. New York: The Roland Press, 1950.

Neill, S. A. The persistence of fear reduction resulting from response prevention. Unpublished masters thesis, University of Rhode Island, 1980. 
Page, $H$. The facilitation of experimental extinction by response prevention as a function of the acquisition of a new response. Journal of Comparative and Physiological Psychology, 1955, 48, 14-16.

Page, H., \& Hall, J. Experimental extinction as a function of prevention of a response. Journal of Comparative and Physiological Psychology, $1953,46,33-34$.

Pinel, J., \& Cooper, R. Demonstration of the Kamin effect after one-trial avoidance learning. Psychonomic Science, 1966, 4, 17-18.

Rachman, S. Studies in desensitization: II. Flooding. Behaviour Research and Therapy, 1966, 4, 1-6.

Rachman, S., Marks, I., \& Hodgson, R. The treatment of obsessivecompulsive neurotics by modelling and flooding in vivo. Behaviour Research and Therapy, 1973, 11, 463-471.

Ransey, P. Exact type I error rates for robustness of student's $\underline{t}$ test with unequal variances. Journal of Educational Statistics, 1980, 5 , 337-349.

Rescorla, R., \& Solomon, R. Two-process learning theory: Relationships between Pavlovian conditioning and instrumental learning. Psychological Review, 1967, 74, 151-182.

Reynierse, J., \& hiff, L. Effects of temporal placement of response prevention on extinction of avoidance in rats. Behaviour Research and Therapy, 1973, 11, 119-124.

Rohrbaugh, M., \& Riccio, D. Paradoxical enhancement of learned fear. Journal of Abnormal Psychology, 1970, 75, 210-216.

Rohrbaugh, M., Riccio, D., \& Arthur, A. Paradoxical enhancement of conditioned suppression. Behaviour Research and Therapy, 1972, 10, 125-130. 
Schiff, R., Smith, N., \& Prochaska, J. Facilitation of extinction of an avoidance response by response blocking. Journal of Comparative and Physiological Psychology, 1972, 81, 356-359.

Schoenfeld, w. An experimental approach to anxiety, escape and avoidance behavior. In P. H. Hoch and J. Zubin (Eds.), Anxiety, New York: Greene and Stratton, 1950.

Seligman, M., \& Johnston, J. A cognitive theory of avoidance learning. In F. J. MCGuigan and D. B. Lumsden (Eds.), Contemporary approaches to conditioning and learning, washington, D.C., V. H. Winston, 1973.

Skinner, B. F. Pigeons in a pelican. American Psychologist, 1960, 15, $28-37$.

Smith, N. F. Effects of interpolated learning on the retention of an escape response in rats as a function of age. Journal of Comparative and Physiological Psychology, 1968, 65, 422-426.

Solomon, R., \& Wynne, L. Traumatic avoidance learning: The principles of anxiety conservation and partial irreversibility. The Psychological Review, 1954, 6l, 353-384.

Spear, N. E. Retrieval of memory in animals. Psychological Review, 1973, 80, 163-194.

Spear, N., Hamberg, J., \& Bryan, B. Forgetting of recently acquired or recently reactiviated memories. Learning and Motivation, 1980, 11, 456-475.

Stampfl, T. Implosive therapy: The theory. V. A. Publication, Battle Creek, Michigan, 1966.

Stampfl, T., \& Levis, D. The essentials of implosive therapy: A learning therapy. Journal of Abnormal Psychology, 1967, 72, 496-503. 
Starr, M., \& Mineka, S. Determinants of fear over the course of avoidance learning. Learning and Motivation, 1977, 8, 332-350.

Stone, N. S., \& Borkovec, T. D. The paradoxical effect of brief CS exposure on analogue phobic subjects. Behaviour Research and Therapy, $1975, \underline{13}, 51-54$. 
Footnote

I It should be noted that the term 'fear' is used in both a theoretical and an operational context in this paper. As Mineka (1979) points out, the theoretical state of fear accompanying avoidance behavior is assumed to be a complex construct and that fear emerges as the result of pairing a neutral stimulus with a noxious stimulus. A number of different response systems have been shown to be sensitive to this conditioning procedure including facilitation and maintenance of ongoing operant avoidance behavior in the presence of a CS, suppression of ongoing operant appetive behavior, and passive avoidance of a CS, among others. Each has been validated as a fear index to some degre by showing its sensitivity to changes in the parameters of the pairing of the neutral and noxious stimuli. These procedures, of course, presume that there is a positive correlation between the magnitude of a response in the observable response system and the internal state of fear, even though research has shown that these observable response systems do not covary. It then follows that a treatment which is designed to reduce the internal state of fear may have an effect on a particular response system and not others. In this paper the conceptual use of 'fear' refers to the central state representing the predictive contingency between the CS and UCS. 'Increases in fear' or 'fear enhancement' refers to the strengthening of the contingency while 'decreases' in fear refer to the. weakening of the contingency. 'Fear' as an operational term refers to the direct measurement of the subject's overt behavior by persistence of avoidance, "CER," or passive avoidance techniques. 


\section{Appendix A}

Analysis of Variance Summary Table for Total

Trials to Avoidance Acquisition Criterion

\begin{tabular}{lccccc}
\hline Source & Sum of Squares & df & Mean square & F & E \\
\hline Treatment & 306.87 & 2 & 153.43 & 1.63 & n.s. \\
$\begin{array}{l}\text { Treatment } \\
\text { Delay } \\
\text { Interval }\end{array}$ & 421.37 & 3 & 140.46 & 1.49 & n.s. \\
Interaction & 593.53 & 6 & 98.92 & 1.05 & n.s. \\
Error & 10156.60 & 108 & 94.04 & & \\
Total & 11478.37 & 119 & 106.28 & & \\
\hline
\end{tabular}




\section{Appendix B}

Analysis of Variance Summary Table for Number

of Shocked Trials to Avoidance Training Criterion

\begin{tabular}{lccccc}
\hline Source & Sum of Squares & df & Mean Square & $\underline{F}$ & $\underline{\text { n.s. }}$ \\
\hline $\begin{array}{l}\text { Treatment } \\
\begin{array}{l}\text { Treatment } \\
\text { Delay } \\
\text { Interval }\end{array}\end{array}$ & 70.62 & 2 & 35.31 & 1.65 & \\
Interaction & 133.58 & 6 & 22.26 & 1.04 & n.5. \\
Error & 2309.60 & 108 & 21.39 & & \\
Total & 2545.47 & 119 & 23.57 & & \\
\hline
\end{tabular}




\section{Appendix C}

Analysis of Variance Summary Table for Total

Shock Duration to Avoidance Training Criterion

\begin{tabular}{lccccc}
\hline Source & Sum of Squares & df & Mean Square & $\underline{E}$ & $\underline{\text { Q }}$ \\
\hline Treatment & 829.40 & 2 & 414.70 & 3.14 & n.s. \\
$\begin{array}{l}\text { Treatment } \\
\text { Delay } \\
\text { Interval }\end{array}$ & 462.90 & 3 & 154.30 & 1.17 & n.s. \\
Interaction & 550.52 & 6 & 91.75 & 0.69 & n.s. \\
Error & 14280.45 & 108 & 132.23 & & \\
Total & 16123.27 & 119 & 135.49 & & \\
\hline
\end{tabular}


Appendix D

Analysis of Variance Summary Table for a Log

Transformation on Approach Latency

\begin{tabular}{|c|c|c|c|c|c|}
\hline Source & Sum of Squares & $\underline{d f}$ & Mean Square & $\underline{F}$ & P \\
\hline Treatment & 34.45 & 2 & 17.22 & 60.00 & . \\
\hline $\begin{array}{l}\text { Treatment } \\
\text { Delay } \\
\text { Interval }\end{array}$ & 0.14 & 3 & 0.05 & 0.16 & n.s. \\
\hline Interaction & 2.96 & 6 & 0.49 & 1.73 & n.s. \\
\hline Error & 30.85 & 108 & 0.29 & & \\
\hline Total & 68.39 & 119 & 0.57 & & \\
\hline
\end{tabular}


Appendix $E$

Analysis of Variance Summary Table for a Log Transformation on Approach Latency for the One Minute Treatment Delay Interval

\begin{tabular}{lccccc}
\hline Source & Sum of Squares & df & Mean Square & $\underline{F}$ & $\mathrm{E}$ \\
\hline Treatment & 18.70 & 3 & 6.23 & 30.17 & .01 \\
Error & 7.43 & 36 & 0.21 & & \\
Total & 26.13 & 39 & 0.67 & & \\
\hline
\end{tabular}


Appendix $F$

Analysis of Variance Summary Table for a Log Transformation on Approach Latency for the 49 Day Treatment Delay Interval

\begin{tabular}{lccccc}
\hline Source & Sum of Squares & df & Mean Square & $\underline{F}$ & $\underline{\mathrm{p}}$ \\
\hline Treatment & 24.57 & 3 & 8.19 & 28.23 & .01 \\
Error & 10.44 & 36 & 0.29 & & \\
Total & 35.01 & 39 & 0.90 & & \\
\hline
\end{tabular}




\section{Appendix G}

Analysis of Variance Summary Table for a Log Transformation on Approach Latency for Control Groups

\begin{tabular}{lccccc}
\hline Source & Sum of Squares & $\underline{d f}$ & Mean Square & $\underline{F}$ & $\underline{\text { n.s. }}$ \\
\hline Treatment & 0.02 & 1 & 0.02 & .25 & \\
Error & 1.45 & 18 & 0.08 & \\
Total & 1.47 & 19 & 0.08 & \\
\hline
\end{tabular}


Appendix $\mathrm{H}$

Analysis of Variance Summary Table

for Total Grid Time

\begin{tabular}{lccccc}
\hline Source & Sum of Squares & df & Mean Square & F & P \\
\hline Treatment & 115706655.70 & 2 & 57853327.85 & 41.82 & .01 \\
$\begin{array}{l}\text { Treatment } \\
\text { Delay }\end{array}$ & 5238308.68 & 3 & 1746102.89 & 1.26 & n.s. \\
$\begin{array}{l}\text { Interval } \\
\text { Interaction }\end{array}$ & 7237913.35 & 6 & 1206318.89 & 0.87 & n.s. \\
Error & 149396303.10 & 108 & 1383299.10 & & \\
Total & 277579180.83 & 119 & 233259.82 & & \\
\hline
\end{tabular}




\section{Appendix I}

Analysis of Variance Summary Table for an Arcsine Transformation on Total Grid Time for the One Minute Treatment Delay Interval

\begin{tabular}{lccccc}
\hline Source & Sum of Squares & df & Mean Square & F & P \\
\hline Treatment & 10.56 & 3 & 3.52 & 27.43 & .01 \\
Error & 4.62 & 36 & 0.13 & \\
Total & 15.18 & 39 & 0.39 & \\
\hline
\end{tabular}




\section{Appendix J}

Analysis of Variance Summary Table for an Arcsine Transformation on Total Grid Time for 49 Day Treatment Delay Interval

\begin{tabular}{lccccc}
\hline Source & Sum of Squares & df & Mean Square & $E$ & E \\
\hline Treatment & 10.78 & 3 & 3.59 & 27.56 & .01 \\
Error & 4.69 & 36 & 0.13 & \\
Total & 15.47 & 39 & 0.40 & \\
\hline
\end{tabular}


Appendix $K$

Non Parametric Examination of Total Grid Time at Treatment

Delay Intervals Including Control Groups

A. Treatment at One Minute Ireatment Delay Interval

\section{Treatment Groups}

\begin{tabular}{|c|c|c|c|c|}
\hline & SPP & NRP & ERP & Con \\
\hline & 22 & 19 & 6 & 1 \\
\hline & 24 & 21 & 11 & 2 \\
\hline & 26 & 23 & 12 & 3 \\
\hline Ranks & 30 & 25 & 13 & 4 \\
\hline & 32 & 27 & 14 & 5 \\
\hline & 33 & 28 & 15 & 7 \\
\hline & 36 & 29 & 17 & 8 \\
\hline & 38.5 & 31 & 18 & 9 \\
\hline & 38.5 & 34 & 20 & 10 \\
\hline & 38.5 & 38.5 & 35 & 16 \\
\hline Total & 318.5 & 275.5 & 161.0 & 65.0 \\
\hline
\end{tabular}

$\mathrm{n}=10, \mathrm{~N}=40$

$\mathrm{H}=\frac{12}{\mathrm{~N}(\mathrm{~N}+1)} \sum_{i=1}^{K} \frac{\mathrm{T}^{2}}{\mathrm{n}}-3(\mathrm{~N}+1)=28.82 \sim \mathrm{x}^{2}, \mathrm{Q} .01$

$C=1-\frac{\sum_{k}^{j}}{N^{3}-N}=.999$

$\mathrm{H}^{\prime \prime}=\frac{\mathrm{H}}{\mathrm{C}}=28.85, \mathrm{P}^{<.01}$

Tukey's procedure for pairwise comparisons after the significant Kruskal-malles test indicated that the control group differed significantly from both the NRP and SRP groups $(\underline{\mathrm{g}}<.01)$ and that the ERP groups differed from the SRP group ( $\mathrm{p}<.05)$. 
B. Treatment at 49 Day Treatment Delay Interval

\section{Treatment Groups}

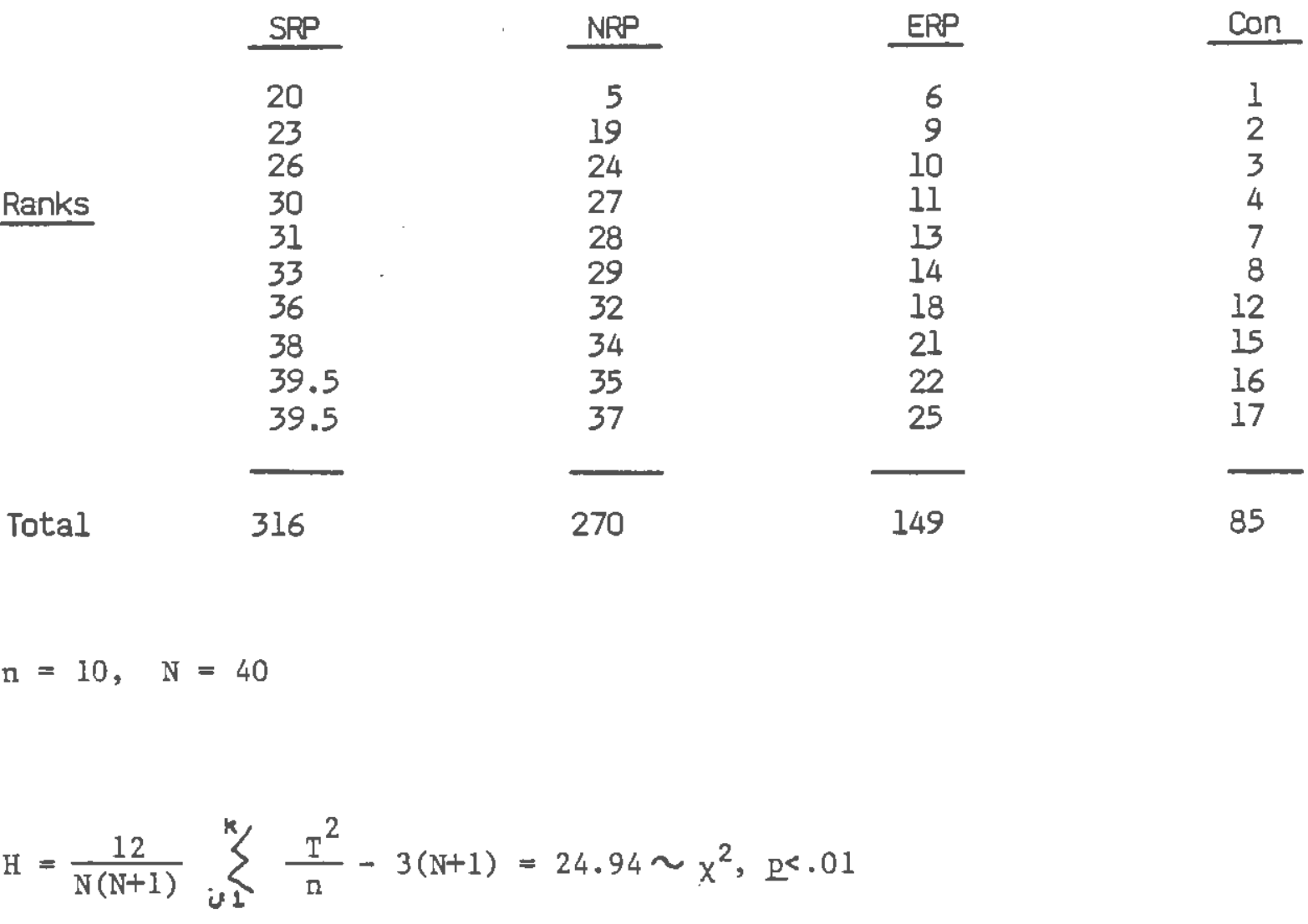

Tukey's procedure for pairwise comparisons after the significant Kruskal-halles test indicated that the control group differed significantly from both the NRP and SRP $(\mathrm{p}<.01)$ and that the ERP group differed from the SPP group $(\mathrm{p}<. \mathrm{Ol})$. 


\section{Appendix L}

Analysis of Variance Summary Table for an Arcsine Transformation on Total Grid Time for Control Groups

\begin{tabular}{lccccc}
\hline Source & Sum of Squares & df & Mean Square & $F$ & $\underline{p}$ \\
\hline $\begin{array}{l}\text { Treatment } \\
\text { Delay } \\
\text { Interval }\end{array}$ & 0.0484 & 1 & 0.0484 & 4.31 & n.s. \\
Error & 0.2023 & 18 & 0.0112 & & \\
Total & 0.2507 & 19 & 0.0132 & & \\
\hline
\end{tabular}

